\title{
Student Attitudes Toward Two Different Online Homework
}

\author{
Leena Yusra Nabulsi* \\ Department of Chemistry and Biochemistry, University of Oklahoma \\ 101 Stephenson Parkway, Norman, OK 73019 \\ E-mail: nabulsil@ou.edu \\ Oluwatobi Odeleye, Ph.D. \\ Department of Chemistry and Biochemistry, University of Oklahoma \\ 101 Stephenson Parkway, Norman, OK 73019 \\ E-mail: oodeleye@ou.edu
}

\begin{abstract}
In recent years, educators have attempted to use various methods of engagement with technology to improve student attitudes toward scientific fields. One method is shifting to online homework (OHW) systems. Attitudes toward two types of $\mathrm{OHW}$ are analyzed through administering surveys to students at the end of a first semester General Chemistry course. Results indicate a complicated relationship between attitudes and OHW. The traditional-responsive system is praised by students to be easy to manage, and the adaptive-responsive for its indepth questions. Traditional-responsive system was criticized for oversimplifying and adaptive-responsive fore complexity. Furthermore, responses show there is a more complex interaction than just with the OHW system itself. Instructors should take care when selecting OHW systems for use in their classroom.
\end{abstract}

Keywords: Online Homework, Student Attitudes, Qualitative Research, Adaptive-Responsive Systems, Traditional-Responsive Systems

DOI: $10.7176 / \mathrm{JEP} / 12-6-03$

Publication date: February $28^{\text {th }} 2021$

\section{Introduction}

Studies have shown that in recent years, student attitudes towards Science, Technology, Engineering, and Mathematics (STEM) have been increasingly less positive. (Kennedy, Quinn, \& Lyons, 2018; Potvin \& Hasni, 2014). Several techniques have been implemented by researchers and instructors to attempt to improve student attitudes towards STEM fields, including the attempt to increase student engagement with course materials(Heflin, Shewmaker, \& Nguyen, 2017; PECK). This is important because engagement with course material has been shown to be important in providing students a way to have a more positive attitude toward learning the subject(Erdoğdu, 2019). Engagement techniques (both in and out of the classroom) such as flipped classrooms, in-class problems and lecture videos and textbook readings outside of class(Hibbard, Sung, \& Wells, 2015; Schiller, 2013), as well as the use of clickers or smartphones in the classroom to answer questions during lectures have been used in attempts to increase student engagement. An example of engagement in the classroom is the use of in-class problems, which have been used to help instructors measure student content knowledge and understanding in real time (Heflin et al., 2017). As far as out-of-class methods, online homework systems have been used method to help increase student engagement with the course material (Erdoğdu, 2019; PECK).

For this study, attitudes are "a set of affective reactions toward the attitude object, derived from the concepts or beliefs that the individual has concerning the object, and predisposing the individual to behave in a certain manner towards the attitude object"(Shaw, 1967) and encompasses “....an existing predisposition to respond to social objects which [in the presence of interaction with several variables], guides and directs the overt behavior of the individual.'(Shaw, 1967) Attitudes are important because they can be predictors of academic success(Adesoji, 2008; Simpson, 1975; Willson, 1983). In this study, attitudes toward the online homework system and course are looked into, and how potentially behavior can be affected.

Outside of class, the use of online homework systems (OHW)(Balta, Perera-Rodríguez, \& Hervás-Gómez, 2017; Fyneweaver, 2008; Liberatore, 2011; Parker \& Loudon, 2012; Richards-Babb, Drelick, Henry, \& Robertson-Honecker, 2011) is one way that has been used to try to improve attitudes toward STEM courses. Liberatore $^{10}$ used the Sapling Learning OHW in a chemical engineering course and compared its use to traditional textbook written problems. For the Sapling homework, students were given three attempts per problem, and were penalized by $5 \%$ for each extra attempt used to answer the question if they did not get the correct answer the first time. The homework system also provided students with feedback on what parts of the question were incorrect, and at the end gave step-by-step solutions. Liberatore found that student achievement was significantly higher in students that were in the section using Sapling Learning (OHW section). Student attitudes toward the homework were measured and were overall very positive. Students perceived the additional tools (hints, explanations, extra attempts, etc.) of Sapling Learning to be helpful(Liberatore, 2011) because they 
allowed students to interact with the material and give them more chances to understand the material.

In Organic Chemistry, Malik et al.(Malik, Martinez, Romero, Schubel, \& Janowicz, 2014) used Connect (an OHW system) and compared its use to written homework. One section of students was given the Connect system as their homework in an online format, while the other section was given the same problems to be completed for written assignments and turned in to the professor. Student attitudes were evaluated for this study through anonymous surveys distributed to students at the end of the semester. Students overall had a more positive interaction with the online homework than with the written homework. Positive comments toward OHW included the aspects of multiple attempts and instant feedback.

With OHW having student feedback being positive based on previous research, various companies have sought to produce their own OHW systems(Learning, 2018; Pearson, 2019; WileyPLUS, 2019), and currently, two types of OHW have been developed. The first type of OHW system works by giving the same problems (sometimes in a different order for individual students) and allowing multiple attempts for each problem (3-5 tries usually). After an incorrect attempt, the system gives a hint or explanation. This gives students immediate feedback on their own tries about what they could be doing wrong, which could explain why online homework systems improve student success - immediate motivation for students to review and actively learn the material. These types of systems have been called "traditional-responsive" OHW systems, and some examples include Sapling Learning(Learning, 2018), WileyPLUS(WileyPLUS, 2019), and Mastering Chemistry(Pearson, 2019).

Richards-Babb et al. conducted a study using a traditional-responsive OHW (WileyPLUS), giving students 18 total assignments with around 19-20 questions and three attempts per question. The purpose of this study was to view the effectiveness of the OHW in student success as well as learning about student attitudes toward the $\mathrm{OHW}$. In order to measure student success, homework and student grade data were used and statistical significance was shown in grades compared to the use of quizzes as formative assessment before the online homework system, favoring OHW participation(Richards-Babb et al., 2011). In order to get an idea of attitudes of the students, a self-report survey was given to students. Most students in the course reported that the OHW was worth the effort put in and relevant to what the class was teaching at the time. Students also reported that they felt the system improved their exam grades and overall course grades. This demonstrates a positive attitude toward OHW systems and is further supported by the $85 \%$ of (total $\mathrm{N}=290$ ) students recommending that $\mathrm{OHW}$ continue being used(Richards-Babb et al., 2011).

The second type of OHW system, developed more recently, is the "adaptive-responsive" system. This type of system include systems such as MindTap(Cengage, 2019) and Assessment of LEarning in Knowledge Spaces (ALEKS)(Hill, 2019). The systems begin with finding the baseline of knowledge of each student by using an initial knowledge space determination using artificial intelligence (AI) and an initial test to help determine an individualized plan of topics to cover throughout the course(Hill, 2019). These systems give different questions to each student and continue to adapt the difficulty of questions as students get the questions correct or incorrect. Because of the newness of these systems, there are fewer studies utilizing these systems.

In another study by Richards-Babb et al. the two different types of systems (traditional vs adaptive) were compared. Richards-Babb et al. looked at student achievement in each section to compare the effectiveness of these different systems in student success rates in general chemistry $(\mathrm{N}=8456$ Traditional-responsive, $\mathrm{N}=8557$ adaptive-responsive). Additionally, students were administered open-ended survey to students of the adaptiveresponsive section $(\mathrm{N}=311)$ in order to gather student opinions about the adaptive-responsive system. The results about performance indicated that students who utilized ALEKS performed significantly better than those who utilized Sapling Learning. However, their survey results indicated that students seemed to have a less positive attitudinal response to the adaptive system, as students felt they were spending too much time on it and not getting enough understanding(Richards-Babb, Curtis, Ratcliff, Roy, \& Mikalik, 2018).

The purpose of this study was to understand the attitudes of students to two types OHW systems, Sapling Learning(Learning, 2018), a traditional-responsive system, and ALEKS(Hill, 2019), an adaptive-responsive system. This is significant research because it looks at student views of both systems, rather than just one system. The beliefs and perceptions of these homework systems make up part of student attitudes, which can influence their overall beliefs and perceptions of the subject, as well as even their achievement in the subject. To address this purpose, four questions were asked:

What are students' attitudes toward the two different online homework systems?

What are students' beliefs about the two different OHW systems toward their learning?

Do student attitudes toward the subject of chemistry differ between section and if so, how?

How much chemistry do students believe they have learned? Does this differ by section?

These are important questions to ask because they will help to tell a story about student attitudes toward online homework systems. The perceptions that can be elicited from students is one that can help instructors as they think about OHW systems and other ways to assign homework. 


\subsection{Theoretical Framework}

When conducting research, it is important to frame the question with the mindset of a learning theory in order to help draw conclusions. This is important because the mindset approached while looking at student attitudes can influence how conclusions are drawn. In this study, social constructivism was used as a framework. Social constructivism was developed by Vygotsky as a response (expansion) to Piaget's constructivism. Vygotsky argued that learning occurred through social interactions as well as through internal reactions. The viewpoint of social constructivism is also a common theme in science education(Driver, Asoko, Leach, Scott, \& Mortimer, 2016; Khourey-Bowers \& Fenk, 2017; O’Connor, 2015; PECK). However, very few researchers have approached online chemistry homework with this approach(Woo \& Reeves, 2007). The analysis approach views the interactions between user and software influence learning and attitudes, as well as how students deal with the information they are learning. It becomes a matter of the students' beliefs about the intrinsic value associated with the interactions of each software. Interactions with OHW systems can be considered social because the feedback in both ALEKS and Sapling is tailored toward the response given by the student. This leads to an interaction with the system in analyzing what it says and comparing it to the work previously done to construct a new understanding of the problem and the topic, also giving students more chances to succeed and expand their learning.

\section{Methods}

\subsection{Participants and Study Design}

This study was approved by the Institutional Review Board (IRB) at the institution where the study was conducted. Participants for this study were students enrolled in a General Chemistry I course (CHEM 1315) in the Fall 2018 semester at a large, midwestern, institution comprised of mostly undergraduate students. For this study, two different sections taught by the same instructor were given the opportunity to complete an online survey. The only difference between these two sections was the OHW system that was used. The online survey was emailed to all students in both sections and the study participants were those students who chose to complete the survey. Table 1 gives a breakdown of the participants of this study and the online homework system used by each section.

Table 1. Information for study participants and online homework used.

\begin{tabular}{|l|l|l|}
\hline & Section 001 - ALEKS & Section 002 - Sapling \\
\hline $\begin{array}{l}\text { Total Enrollment (including students that withdrew from the } \\
\text { course) }\end{array}$ & 305 & 308 \\
\hline Enrollment after withdrawal & 241 & 261 \\
\hline Study particpants & $66(22 \%)$ & $47(15 \%)$ \\
\hline DFW rates & $21 \%$ & $21 \%$ \\
\hline Withdrawal rates & $11 \%$ & $12 \%$ \\
\hline Average ACT score & 26.8 & 26.5 \\
\hline
\end{tabular}

A total of 113 students, 66 using ALEKS and 47 using Sapling, responded to surveys regarding their attitudes towards their respective homework systems.

To answer the research questions, open-ended survey questions (shown in table 2) were emailed to the participants to determine their attitudes towards their online homework system.

Questions 1 and 7 elicited grade change perspectives from students. Questions 2 and 3 were meant to get student perspectives on chemistry and how this specific course has impacted student views of chemistry. Question 4 asks students their attitude toward the homework system, Question 5 about their perception of how much chemistry has been learned and finally, Question 6asks what students' perceptions of the system's impact on their learning is.

Table 2. Survey instrument

What is your current grade in CHEM 1315?

How do you feel about chemistry? Why?

How has CHEM 1315 influenced the way you view chemistry?

How do you feel about the current homework system being used in your class? Why?

How much chemistry do you believe you've learned this semester? Why?

How has the current homework system impacted your learning of chemistry this semester?

What do you think your final grade in CHEM 1315 will be?

\subsection{Online Homework Systems Used}

The online homework used as the traditional homework was Sapling Learning. Students were given approximately 10-20 questions and 5 attempts per problem, with no penalty for extra attempts used. Hints and explanations were available after each attempt. Each student received the same question, with different numbers 
and could work through them in any order they chose. The correct answers were visible to students after the due date for any problem that they did not answer correctly after 5 tries.

As the adaptive-responsive system, Assessment of LEarning in Knowledge Spaces (ALEKS) was used. Students who were assigned ALEKS homework were given certain topics to master each week. In order to master those topics, three questions in a row had to be answered correctly. Two attempts were given per question for a correct answer. If a student failed to answer correctly, the progress would be reset. For example, if a student correctly answers the first and second question on the first try, they move on to the third question, and if they answer that question correctly they are allowed to move on. If it is answered incorrectly, they receive another attempt, but if they answer it incorrectly a second time, they must restart back at the first question and are given a new question set to work through. Additionally, students were required to complete knowledge checks every 23 weeks. These knowledge checks were additional assignments following the same structure that reviews material covered previously in the course. This feature of knowledge checks was not mirrored in the Sapling Learning homework system and was unique to ALEKS users.

\subsection{Data Analysis}

The responses to questions 2) through 6) in table 2 were analyzed using the inductive thematic analysis method (Cresswell \& Poth, 2018). Themes and patterns were found in the data and data were grouped according to their similarities. The responses to question 2 were coded in four ways: "I like the system", "I have a love/hate relationship with the system", "I don't really care either way/neutral", and "I dislike the system". In order to ensure interrater reliability(Clark, 2018), each author coded responses based on these categories, and if disagreement in the coding was found, it was discussed until a consensus was reached. For question 6 , there were three categories: "the system has helped me learned", "system hasn't helped me learn" and "something in between". These responses were then categorized to identify themes of attitude based on the general attitudes toward chemistry (question 2), the course (question 3), and how much chemistry students learned (question 5) to identify patterns in these groups about perceived success in the course.

\section{Results and Discussion}

3.1 Research Question 1: What are students' attitudes toward different online homework systems?

In addressing this first question, responses to question 4) of the survey were analyzed (Table 2). Question 4 asked: How do you feel about the current homework system being used in your class? Why?

These responses indicate that a majority of students held positive attitudes about the online homework system used, shown by the responses of $53 \%$ and $62 \%$ of ALEKS and Sapling users, respectively, having responses categorized as "I like the system" (Table 3 ). Comments about liking the system are related to receiving multiple attempts, such as this student that utilized ALEKS stating: " $i$ love it, it's interactive, helps me learn how to do the problems instead of having to be stuck on a problem that I can't solve." And this Sapling student stating: "I like it. It's practical, clear and the fact that it gives us 5 chances to get the answer right makes it even better". The difference that seems to be shown here is that the student commenting about ALEKS refers to the changing questions for variety, while the Sapling user held a positive attitude toward the system because they had a static question. This changing of questions was a key factor in many responses from students who used ALEKS (shown further in this section).

Table 3: Student Attitudes Towards the System

\begin{tabular}{|l|l|l|}
\hline & $\begin{array}{l}\text { ALEKS } \\
(\mathrm{n}=66)\end{array}$ & Sapling $(\mathrm{n}=47)$ \\
\hline I like the system & $35(53 \%)$ & $29(62 \%)$ \\
\hline I have a love/hate relationship with the system & $19(29 \%)$ & $3(6 \%)$ \\
\hline I don't really care either way/neutral. & $2(3 \%)$ & $7(15 \%)$ \\
\hline I dislike the system & $10(15 \%)$ & $3(6 \%)$ \\
\hline Other (comparison of the two HW systems) & $0(0 \%)$ & $4(9 \%)$ \\
\hline No Comment & $0(0 \%)$ & $1(2 \%)$ \\
\hline
\end{tabular}

Another key factor for students liking (or disliking, as will be shown) ALEKS was the knowledge checks. One student response sums the overall feeling up with: "I like using ALEKS because it does the knowledge checks to ensure that I actually learned what I was supposed to know about chemistry". This type of comment 
was not made by students using Sapling due to not having this feature. Tying this back to Vygotsky's idea, these knowledge checks are a special feature of ALEKS, leading to different interactions with the software than what students with Sapling have, and can help attribute to these attitudinal differences.

Changing questions, called "loss of progress" in most responses, were featured in many responses of those who were coded as "dislike the system" (ALEKS 15\% n=10; Sapling 6\% $n=3$, Table 3). This is showcased in the ALEKS student comments such as: "I do not like ALEKS. It is a hard system to gauge, and I don't like that progress is continually taken away". This response exemplifies the other end of the student opinion about the changing questions (or loss of progress) as it is viewed by students who commented on disliking the system. The knowledge checks were an additional reason that students did not like the system, summarized by this student's comment: "Aleks does not feel good. The weekly non optional knowledge checks that take 30 minutes to complete and have no grade impact make me dread starting the homework.".

The continual adaptation of questions and knowledge check feature seem to be the driving force for why more students dislike the system, but also seem to be the important factor in the large disparity of responses from students about having a "love/hate relationship" (ALEKS 29\% $\mathrm{n}=19$, Sapling 6\% $\mathrm{n}=3$; Table 3) with their assigned system. This theme emerged from comments about ALEKS such as: "It is a love hate relationship. I feel I learn topics better than students using the other homework system, but at the same time the knowledge checks can be frustrating" and another comment expressing "I have 50/50 about aleks. I like it but not really. I like the knowledge checks to make sure you are understanding but there is so many questions that they give. Also, when you are doing a regular assignment, I do not like how it takes away the ones you got correct if you get one wrong." Both comments discuss the ambivalent feelings that most ALEKS users articulated toward the adaptive nature of ALEKS and its knowledge check feature.

In contrast with this, Sapling users who had a love/hate relationship commented about software interaction with a comment: "I like it but I don't like it when it asks us to draw Lewis structure and other problems, like electron configuration, that took so much time just enter the answers" and another, "It's pretty good. Sometimes hard to use".

These comments are also tied to how students interact with and use the system. With comments addressing the loss of progress and knowledge check, it is a discussion by students about how they interact with the system and how they view that feedback, such as how long knowledge checks can take or progress being lost (for ALEKS) and various user interface aspects discussed by the students using Sapling. These interactions influence how students view the software in both a positive and negative way, which is what lead to the ambivalence of these comments.

Neutral responses were found with both groups, however, more Sapling students had a neutral opinion about their system $(15 \% \mathrm{n}=7)$ than ALEKS users $(3 \% \mathrm{n}=2)$ (Table 3). Sapling responses exemplifying the neutrality are statements such as: "I find it to be adequate"; "It's fine" and "Sapling is okay". The ALEKS responses were about paper and pen homework ("It doesn't help as easily as paper homework") and length of homework in general ("I feel as though it would be beneficial to have a slightly lesser amount of homework each week to allow more time for studying").

Interestingly, another categorization as "Other" came up in the Sapling student responses that were not seen in the ALEKS responses. This was a comparison of the two homework systems, with ALEKS seeming to be more advantageous to students who were utilizing Sapling, summarized by one student noting that: "It's fine, ALEKS is probably better 'cause it seems like you learn more.". This is elaborated on by another student with the acknowledgement of guessing in homework remarking: "I feel sapling isn't as good as aleks because with sapling on the multiple choice questions we can just guess until we get the answer but with aleks it gives you a new question so you have to actually know or learn the topic and not just guess".

As instructors, we strive for the best learning for our students. The opinion of students can be used to improve classroom experiences by helping to implement systems that students enjoy using and seem to have a positive view of. It seems that overall, attitudes toward both systems are mostly positive, but that for those students who have opinions regarding ALEKS, these opinions tend to be more polarized. Looking at the feedback, it does seem that knowledge checks divide the students who used ALEKS as a feature that was helpful, or a feature that was frustrating.

This could be indicative of students who were not using the system as effectively because these students may view homework as separate from studying, and the knowledge checks should be the way that students are consistently studying instead of cramming. Indeed, this could be supported by the idea presented by RichardsBabb previously, where this type of system (ALEKS) helped students change their study habits(Richards-Babb et al., 2018). Perhaps one way to present this system to students would be to share the features and explain that this feature of knowledge checks and adaptation should be able to reduce the time outside of homework and class needed for studying; as long as students put their effort into answering these questions thoughtfully. 
3.2 Research Question 2: What are students' attitudes about the different OHW systems toward their learning? In order to address this question, the survey responses to question 6) "How has the current homework system impacted your learning of chemistry this semester?" (Table 2). There were three total categories of responses: "helped me learn", "did not help me learn", and "something in between". The something in between category was coded as students who did not respond directly about the system's impact on their learning or made comments other than just about the perceived impact on learning.

Table 4. Student Perceived Learning Impact

\begin{tabular}{|l|l|l|}
\hline & ALEKS (n=66) & Sapling $(\mathrm{n}=47)$ \\
\hline The system has helped me learn & $51(77 \%)$ & $30(64 \%)$ \\
\hline Something in between & $5(8 \%)$ & $5(11 \%)$ \\
\hline The system has not really helped me learn & $9(14 \%)$ & $11(23 \%)$ \\
\hline No comment & $1(2 \%)$ & $1(2 \%)$ \\
\hline
\end{tabular}

For students who used ALEKS, 77\% of students felt that the system had a positive impact on their learning, and $64 \%$ of students felt that Sapling had a positive impact on their learning (Table 4). The comments for both were very similar, stating that the homework system allowed students learn and master the material being taught and discussing the opportunity for multiple attempts, which is positively received by the students. ALEKS gives different problems to students based on their level of mastery and will adapt as students get answers right or wrong, whereas Sapling gives the same questions to all students, in a different order, but still students felt this helped them learned, as shown in this students comment about why they felt Sapling was helpful: "The homework system has helped me apply what I learn in lecture. It gives me good practice. Since I am able to attempt problems multiple times, I better learn from my mistakes". A student using ALEKS had a similar thought, stating: "The homework system allows you to cover the topics throughly until you understand them, and makes sure your foundation is strong." This comment was interpreted to be referencing the adaptive nature of ALEKS in its words of "cover the topics throughly", also acknowledging the foundation building nature of ALEKS from the knowledge checks.

This shows that the feedback and the attempts allowed give students the opportunity to learn through the interaction with the software, prompting students to learn the material because they are given chances to interact with and change their understanding based on the feedback received from the system.

Relatively the similar numbers of students felt neutral about the system or had an ambivalent, "something in between" feeling toward their assigned homework system. Eight percent $(n=5)$ and $11 \%(n=5)$ of students who used ALEKS and Sapling, respectively, had this view (Table 4). Various comments from these students showed they felt homework was not the best way to cover material relevant for the exam, shown in some of the ALEKS users comments: "It has made me aware of what topics to study for future exams but, I don't get the full learning experience out of it" and "it doesn't help so much with the basics and trends, but it helps with the mathematics; meaning that for tests it's not the greatest review tool but it's helpful." These statements summarize the student attitudes by discussing aspects they didn't think were helpful, and aspects that were helpful. Similar responses from students who used Sapling were seen with statements such as: "Overall, I don't feel it is helpful, but there are some questions from the homework helps to me understand the topic" and "I feel like it is helpful, but sometimes it is easy to cheat since we have 5 chances." This last comment about cheating mirrors a comment from the above attitude that Sapling was not as good in the student's eyes because it allowed for guessing. These types of responses should be expected, as all learners are different, and no one homework system can account for all learning types and there will be students who do not gain every benefit from the system or gain more than others and aligns with the idea of individual learners interacting differently with the system.

There were, however, students who had negative attitudes toward how the system impacted their learning. Overall $14 \%$ of ALEKS users and $23 \%$ of Sapling students (Table 4) felt that their learning was not helped by the system that they used. Students using ALEKS who perceived a negative impact on their learning focused on the frustration felt while doing the homework, citing the loss of progress, amount of questions, and knowledge checks as their reasons, some students being very concise with their feelings in expressing: "It has not" and "...it is excessive and annoying." While the first commenter did not elaborate why it did not help this student learn, the second comment here shows much of the frustration of the progress being lost and having to redo problems many times. This interpretation of the student's feeling toward the system is based on the overall comments from students who didn't like the system, as well as these other comments about why they felt ALEKS did not help their learning: “...There are always so many topics and they take so long to complete because of the progress tracker" and "I don't like how if you get a question wrong you have to restart the 
question...Aleks just requires a lot more time to complete when I could be competing other class homework as well." These comments go back to many of the same thoughts about the progress and time that other students had previously discussed in their responses regarding the adaptive nature of their homework.

For students using Sapling, however, the lack of difficulty in their homework was mentioned, as well as the lack of correlation between doing the homework and their exam grades. Take this student sharing their feelings regarding their homework system by stating "The homework is just me pushing to get through to get a good grade. It's the worksheets, study sessions, lecture, and past exams that are actually impacting my learning" and this other student's thoughts that Sapling "is just a completion task to keep and help your grade." This showcases the general feeling that the traditional format of the OHW systems is not what impacts these students' understanding the most. A few of these students also commented on the other class resources that helped them prepare, while others simply wrote statements such as "not much" and "not a lot".

What this demonstrates is the variable nature of social interactions between the learner and the system leaving different perceptions of learning, and to put this in context of Vygotsky's theory, different places reached within the Zone of Proximal Development. Each student had different interactions and understandings to begin with (their actual development) and therefore perceived their learning amounts differently based on those interactions (where they fell within the Zone of Proximal Development).

An interesting finding of these first two research questions regarding attitudinal differences is that there is a strong difference in attitude toward both questions from the students using the adaptive system that is not seen in students who used the traditional method. Using Sapling, the traditional OHW system, 62\% of the students had positive attitudes toward the system and $64 \%$ felt the system had helped them learn. This shows a relatively equal distribution of opinions from students. It is more likely here that students with more positive attitudes towards the system believed they learned more from the homework system. However, responses from students using ALEKS, the adaptive system showed that $53 \%$ of students had a positive attitude toward the system, while a large majority, $77 \%$ of students felt that the system helped them learn (Table 5) Table 5. Comparison of Positive Attitude toward OHW System and Positive Attitude toward learning

\begin{tabular}{|l|l|l|}
\hline & ALEKS $(\mathrm{n}=66)$ & Sapling $(\mathrm{n}=47)$ \\
\hline I like the system & $35(53 \%)$ & $29(62 \%)$ \\
\hline The system has helped me learn & $51(77 \%)$ & $30(64 \%)$ \\
\hline
\end{tabular}

One potential explanation for this difference was exemplified in student comments. While students using ALEKS disliked the time homework and knowledge checks, they also realized the importance of "making sure your foundation is strong" and recognized that this was the purpose of the knowledge checks. Students using Sapling liked it because of the ability to have the five tries, which was cited as both helpful and unhelpful to students due to being able to keep trying but also being able to guess.

It is interesting to note that a typical response from an ALEKS student was longer and more specific, while the typical response from a Sapling student was shorter and had less detail. This could be due to the stronger feelings of students toward the adaptive-responsive homework, shown in the lower percentage of student responses in the neutral range for ALEKS student attitudes toward their system, and more in the negative attitude than for ALEKS students than Sapling students.

Moving forward, instructors can take this feedback and work with the material in helping students work through their homework more efficiently. For Sapling, instructors may be able to reduce the number of attempts to reduce the chances of guessing, and for ALEKS, instructors may be able to explain to students the importance of these knowledge checks. It seems that students already can grasp that these knowledge checks are helpful to their learning, even if they don't enjoy it as much (Table 5). What this tells us is that students understand that these aspects are good, but we as instructors may have to introduce this to students and get students to think about the knowledge checks positively before even encountering them.

\subsection{Research Question 3: Is there a difference between the perceived impact of chemistry learned by section?} Responses to questions 2 and 3 were used to help answer this question (How do you feel about chemistry? Why? And How has CHEM 1315 influenced the way you view chemistry?, respectively).

For question 2, five categories of responses emerged and for question 3, six categories of responses emerged, as shown in Tables 6 and 7. 
Table 6: Summary of responses to Question 2

\begin{tabular}{|l|l|l|}
\hline & ALEKS (n=66) & Sapling (n=47) \\
\hline Positive Attitude toward Chemistry & $39(59 \%)$ & $27(57 \%)$ \\
\hline Neutral Attitude & $9(14 \%)$ & $2(4 \%)$ \\
\hline Negative Attitude toward Chemistry & $12(18 \%)$ & $11(23 \%)$ \\
\hline "Something else" & $6(9 \%)$ & $6(13 \%)$ \\
\hline No Comment & 0 & $1(2 \%)$ \\
\hline
\end{tabular}

Table 7: Summary of responses to Question 3

\begin{tabular}{|l|l|l|}
\hline & ALEKS (n=66) & Sapling $(\mathrm{n}=47)$ \\
\hline Positive Influence & $30(45 \%)$ & $15(32 \%)$ \\
\hline No change & $15(23 \%)$ & $14(30 \%)$ \\
\hline Negative influence & $10(15 \%)$ & $2(4 \%)$ \\
\hline Unclear response & $5(8 \%)$ & $8(17 \%)$ \\
\hline "More to chemistry" & $6(9 \%)$ & $7(15 \%)$ \\
\hline No comment & 0 & $1(2 \%)$ \\
\hline
\end{tabular}

For the students who responded that they had a positive attitude toward chemistry, a common theme in ALEKS student responses were about how they thought the subject is "interesting and fun" or how it "has a lot of real world applications". Another student had a positive attitude toward chemistry by saying, "it gives you an idea of how everything around you is made up and how it reacts with its surroundings". Statements from Sapling students reflected this by saying "I find it a fascinating subject" and "I also enjoy how my professor teaches" while another student mentioned "[Instructor A] is very fun to listen to and keeps me interested in the class".

Nine students who used ALEKS were neutral about the topic, stating that "it's okay" or they were "indifferent to it". Only two students from the Sapling section were also neutral with two making the same "it's okay" comment. What is interesting about these comments is that it doesn't have the same pattern as with the homework systems, where more students using Sapling felt neutral than students using ALEKS.

Twelve ALEKS users negatively viewed chemistry, with some saying that it "stresses me out more than any other class", or even as strongly as to say that they "hate chemistry." Other responses were less extreme, simply referring to chemistry as a "difficult subject" or that they were "neutrally negative Chemistry has been alright so far this semester, but I've just had a bad experience with it since I took AP Chemistry". Eleven students from Sapling also held this negative attitude toward chemistry, with comments ranging from mildly negative to severely negative attitudes. One student commented about the pacing of the class being a reason, stating that it "is definitely uncomfortable. I think I prefer the way you go about physics more than chemistry." An example of the highly negative comment shows a student that very much doesn't like chemistry by saying " $i$ hate it more than any subject $i$ have ever learned. $i$ absolutely hate everything about it". While this is very extreme, only one other student had a similar attitude with the sentiment of hate toward the subject, but most students mimicked the more mild dislike of the subject by saying that it is "difficult," "confusing," or "intimidating."

However, six students from both sections responded in other ways, not directly answering the question. ALEKS students made comments such as they "enjoy class but not lab" or that they are "more of a physics guy", with another student even referring to their dislike of the ALEKS program. Comments from the six students in the Sapling section refer to the course itself stating that "I feel like I am able to grasp the general/critical information but the small detail nit picky items is starting to catch up with me" and "The lectures are very informative, and there is a lot of extra credit opportunities. This class is by far the most time consuming and requires the most detication out of all my classes. Many times it feels like too much for me to handle with all my other responsibilites. However, the class itself is organized and structured very well." 
The responses from students of both sections were fairly similar. Attitudes are more complex and influenced by more than one thing. This is shown in these student responses with comments about other aspects not just related to the homework system that was used as to why they do and don't like chemistry.

Thirty students using ALEKS stated that they felt that this general chemistry course had a positive impact on their attitude toward chemistry with simple comments such as "positively" or that they "like chemistry more" while others cited specific reasons, summarized by these quotes "actually enjoy chem with [Instructor A] because she makes it fun and it seems easier to do" and "presented in an interesting way, so I find it interesting". Fifteen students using Sapling felt that the course itself had a positive influence on their view of chemistry saying "I enjoy the subject and Chem 1315 has only increased my liking" and "it has influenced the way I view chemistry in a very positive way. It makes me want to learn so much more about how so much more works". There were other encouragingly positive comments such as "it has increased my passion for science in general!" "I have gained confidence in the subject" and even a comment saying, "It has made it more positive and encouraged me to feel like I can be successful even in difficult classes." These are encouraging comments because it shows growth from students and a willingness to learn, as well as give students confidence in their own abilities, even outside of chemistry.

Fifteen students from the ALEKS section had comments simply stating, "it hasn't" and that they "still like the subject" or hasn't changed my view. I have always enjoyed it." These comments are very similar to the 14 students from the Sapling section stating, "no" "not changed" "neither positive nor negative".

However, 10 students from the ALEKS section felt that this specific general chemistry course negatively influenced their attitudes toward chemistry. Many of them stated specifically that it "I do not like chemistry because of CHEM 1315" or that it "completely ruined the subject." It is unfortunate to see students be turned away from the subject of chemistry due to the general chemistry course. Only two students from the section using Sapling felt that there was a negative influence on their thoughts about chemistry, saying, "I do not like chemistry" and an extreme comment that "I view it as an evil I must overcome." This second comment comes from one of the students who used the word hate in their attitude toward chemistry. This student specifically mentioned their grade and lack of understanding as the reason.

Again, there were some students who didn't answer the question completely as intended. Five ALEKS users made comments such as, "even if I've never taken a class I can still do well in it if I work hard" and "I need to study harder for every class". Eight Sapling users made similar comments, saying, "it reminded me that chemistry requires a good amount of work" "shows me how important it all is" and "its definitely not a blow off class". One student commented that they felt the course "touch too lightly about too many subjects". While not answering the question, it does show that students are realizing what they need to do for success and that the general chemistry course can still help them achieve outside of class. It is not possible to tell what their attitude about the subject is from these statements.

When coding, another category came to light that needed to be separated from those that didn't completely answer the question. This category is called "more to chemistry" as there were a number of students that cited this as part of how the course impacted their view. A total of six students were put into this category from ALEKS users, with statements such as "helped me view chemistry at a deeper level" and "there's a bigger understanding to it than high school." Seven students from the Sapling section provided responses that could be categorized here with comments such as "learning more about how the elements interact and how they come together" "CHEM 1315 has made me look at chemistry and it's application to life and not just a class and stuff I need to know to get a grade".

This is another category that, while not showing their attitude toward chemistry and how the course has changed it, does show that students think deeper about the material that is presented to them. This mirrors the same in-depth thinking that is shown by student comments about the homework systems and their perceived impact on learning.

This question has an interesting answer because there were more students that viewed chemistry in a more positive light than when they started the course in the ALEKS section than in the Sapling section. This is good because even though these students all received the same lectures and had the same instructor, they did seem to enjoy chemistry more. However, the downside is that still, of the students that felt that the course dulled their views of chemistry, many more of them came from the ALEKS users than the Sapling users. 
Research Question 4: How much chemistry do students believe they have learned? Does this differ by section? Table 8: Summary of responses to Question 4

\begin{tabular}{|l|l|l|}
\hline & ALEKS $(\mathrm{n}=66)$ & Sapling $(\mathrm{n}=47)$ \\
\hline A lot & $47(71 \%)$ & $32(68 \%)$ \\
\hline Some & $6(9 \%)$ & $5(11 \%)$ \\
\hline none/not a lot & $4(6 \%)$ & $2(4 \%)$ \\
\hline Not a lot because of a previous course & $4(6 \%)$ & $6(13 \%)$ \\
\hline Unclear Response & $5(8 \%)$ & $1(2 \%)$ \\
\hline No comment & 0 & $1(2 \%)$ \\
\hline
\end{tabular}

Forty-seven students from the ALEKS section felt that they had learned a lot of chemistry. One student used exam performance as an indicator by saying "pretty much everything that was taught so far due to my performance on exams." Other students said they learned a lot and cited the course material and presentation as the main reason with statements such as "a good amount of chemistry because of lecture, lab, and recitation" as well as "I believe that I have learned a lot $f$ chemistry this semester because [Instructor A] is a solid professor and I have also learned a lot from the help of ALEKS." The mention of the homework system as helpful to learning was mentioned by a few other students with statements such as "I feel like I have learned a lot about chemistry, especially when I complete knowledge checks and I keep my progress" and "I've learned a lot because I feel like we are constantly tested on what we remember with the knowledge checks." The citation of the homework system itself was not as widely spread with the Sapling students as it was with the ALEKS students. Only one student mentioned the homework by saying, "I believe I have learned a lot of chemistry this semester because of how much understanding I gain from lectures, homework, recitation, and lab." Another student commented that they learned "more than I did when the class just started. I had read the list of ingredients no a pill bottle and found to my delight the ability to identify most of the chemicals." Most comments tended to be more generic with "I believe I've learned a lot of chemistry this semester" and "A lot" This mirrors the same tendency in the homework of attitudes and perceptions of learning being different, showing deeper thought and understanding of students.

Six students in the ALEKS section were fairly neutral in how much they learned, with them saying " $a$ decent amount" or "more than half." Five students from Sapling stated that they had learned "enough" "some" or "probably $1 / 2$ of what we've learned"

However, nine students in the ALEKS section and eight students in the Sapling section fell into the category of not learning lot of material. This lead to a new category being identified in student responses: students who didn't learn much because of a previous course in chemistry. The students in the ALEKS section $(\mathrm{N}=4)$ who didn't feel like they learned a lot simply stated things such as "not that much honestly" and "not a lot." The two students in the Sapling students who felt they didn't learn very much of the material stated, " 0 , my grades tell me I am not understanding" and "Not a lot based on my test grades". Five of the ALEKS students stated something along the lines of "everything was review except wavelength because I took APCHEM" and "not too much but that's only because I had a great high school AP chemistry class!" In the six Sapling students who responded this way, the comments were similar with statements such as "not more than I knew before after taking AP chemistry in high school" and "most material is review since I've taken this class before".

There were once again other students in the ALEKS section $(n=5)$ and the Sapling section $(n=1)$ who did not make clear their beliefs about how much was learned. The comments are summarized by them stating that "not as much as I need to have learned" and "I do not feel like I've learned the amount I need." The Sapling student commented "a lot more than I thought I would"

This is ambiguous because students may have a high expectation for what they need to know and have not met that expectation, but it does not mean that they have not learned anything or have only learned very little chemistry. In the case of the Sapling student it could be that they didn't believe they would learn anything and just retaining $15-20 \%$ of the material was considered a lot.

This tells us that regardless of the homework system, most students still felt that they learned a lot of chemistry.

\subsection{Limitations of the Study}

One limitation of this study is low response rate from students. While 241 students were enrolled in the section 
that used the ALEKS OHW system, lending to a $27 \%$ response rate $(66 / 241)$. The same issue is seen in the other section with an $18 \%$ response rate $(47 / 261)$. Another limitation is the categorization of responses to other questions. Some of the answers to the questions from students did not directly address the intent of the question, so perhaps rewording the questions to be more specific can be of use in the future

\section{Conclusions}

As evidenced by student survey responses, there are advantages and disadvantages to both types of systems. Students seem to have stronger feelings toward ALEKS compared to Sapling, shown by their response categorizations and their longer, more specific responses. ALEKS is a more tasking system because of the knowledge checks and adaptive nature of question giving, and some students do not seem to like the extra effort and time required by this system. Adding to this contrast of the systems $53 \%$ of students showed a positive attitude toward the system as a whole, with $77 \%$ of students in the ALEKS section felt the system had a positive impact on their learning; differing from the relatively equal numbers displayed in the Sapling student responses with $62 \%$ of students liking the system and $64 \%$ of survey participants finding Sapling helping their learning.

Overall, no matter the homework type used, most students still felt that they learned a lot of chemistry throughout the semester. Attitudes are complex and are impacted by more than one factor, shown in student responses about their general interest or the way the material was presented, or the helpfulness of the instructor being mentioned in student comments. As stated in the discussion of attitudes, "the presence of interaction with several variables...guides and directs overt behavior"(Shaw, 1967), and the many different factors of an inperson course impact how students interact with and view the course material and tools.

Homework, however, could be a way for students to engage with the material more directly and open up students to what kinds of questions they can ask, and be more specific about their questions, in such a way that they are able to get better responses. Another interesting conclusion is not just student attitudes toward their chemistry homework, but attitudes toward chemistry as a subject. More students who used ALEKS felt that the course negatively impacted their views of chemistry than those who used ALEKS. However, this is countered by nearly half the students of the ALEKS stating the opposite - that they view chemistry in a more positive way. This means that when choosing a system for a course, instructors wishing to have a more lasting impact on students' views of chemistry, will have to weigh the pros and cons of each system before implementing it. It could be that the OHW system chosen played a role in this change of view, and therefore instructors should choose systems carefully when thinking about the lasting impact of their course on student viewpoints.

For instructors wishing to utilize the traditional-responsive systems, students already seem to have a positive attitude toward this system. It may be prudent, however, to reduce the number of attempts on each question in order to encourage students to thoughtfully answer the questions.

For instructors thinking about implementing the adaptive-responsive system such as ALEKS, it may be necessary to share the features of ALEKS to these students beforehand in order to help them approach the semester more positively and already plan to time manage in a better way. If an instructor is wanting to try and influence student viewpoints toward chemistry, this could be the system to choose, as more students using this system seemed to have a change of opinion about the subject, but should be used cautiously, as there could be a negative impact as well.

\section{References}

Adesoji, F. (2008). Managing students' attitude towards science through problem-solving instructional strategy. The Anthropologist, 10(1), 21-24.

Balta, N., Perera-Rodríguez, V.-H., \& Hervás-Gómez, C. (2017). Using socrative as an online homework platform to increase students' exam scores. Education and Information Technologies, 23(2), 837-850. doi:10.1007/s10639-017-9638-6

Cengage. (2019). MindTAP. Retrieved from https://www.cengage.com/mindtap/\#about

Clark, J. W. C. V. L. P. (2018). Designing and Conducting Mixed Methods Research (3rd ed.). Thousand Oaks, California: SAGE Publications.

Cresswell, J. W., \& Poth, C. N. (2018). Data Analysis \& Representation. In Qualitative Inquiry \& Research Design (4th ed.). Great Britain: SAGE

Driver, R., Asoko, H., Leach, J., Scott, P., \& Mortimer, E. (2016). Constructing Scientific Knowledge in the Classroom. Educational Researcher, 23(7), 5-12. doi:10.3102/0013189x023007005

Erdoğdu, M. Y. (2019). The Mediating Role of School Engagement in the Relationship between Attitude toward Learning and Academic Achievement. International Journal of Education and Literacy Studies, 7(2), 75-81.

Fyneweaver, H. (2008). A Comparison of the Effectiveness of Web-based and Paper-based Homework for General Chemistry. Chemical Education, 13(4), 264-269. doi:10.1333/s00897082142a

Heflin, H., Shewmaker, J., \& Nguyen, J. (2017). Impact of mobile technology on student attitudes, engagement, and learning. Computers \& Education, 107, 91-99. doi:10.1016/j.compedu.2017.01.006 
Hibbard, L., Sung, S., \& Wells, B. (2015). Examining the Effectiveness of a Semi-Self-Paced Flipped Learning Format in a College General Chemistry Sequence. Journal of Chemical Education, 93(1), 24-30. doi:10.1021/acs.jchemed.5b00592

Hill, M. (2019). Overview of ALEKS. Retrieved from https://www.aleks.com/about_aleks/overview

Kennedy, J., Quinn, F., \& Lyons, T. (2018). The keys to STEM: Australian Year 7 students' attitudes and intentions towards science, mathematics and technology courses. Research in Science Education, 1-28.

Khourey-Bowers, C., \& Fenk, C. (2017). Influence of Constructivist Professional Development on Chemistry Content Knowledge and Scientific Model Development. Journal of Science Teacher Education, 20(5), 437457. doi:10.1007/s10972-009-9140-0

Learning, S. (2018). Learning Science \& Insights: Science + Empathy + Data Insights. Retrieved from https://www.macmillanlearning.com/college/us/digital/sapling

Liberatore, M. W. (2011). Improved Student Achievement Using Personalized Online Homework for a Course in Material and Energy Balances. Chemical Engineering Education, 45(3), 184-190.

Malik, K., Martinez, N., Romero, J., Schubel, S., \& Janowicz, P. A. (2014). Mixed-Methods Study of Online and Written Organic Chemistry Homework. Journal of Chemical Education, 91(11), 1804-1809. doi:10.1021/ed400798t

O’Connor, C. (2015). A Practice-Led Approach to Aligning Learning Theories with Learning and Teaching Strategies in Third Level Chemistry Education. Irish Journal of Academic Practice, 4(1), 1-17. doi:10.21427/D7B42F

Parker, L. L., \& Loudon, G. M. (2012). Case Study Using Online Homework in Undergraduate Organic Chemistry: Results and Student Attitudes. Journal of Chemical Education, 90(1), 37-44. doi:10.1021/ed300270t

Pearson. (2019). The Learning science behind Pearson Mastering Chemistry. Retrieved from https://www.pearsonmylabandmastering.com/northamerica/masteringchemistry/educators/learningscience/index.html

PECK, S. T. A. D. Can We Do School Science Better? Facing The Problem of Student Engagement Education Canada, 49(2), 54-57.

Potvin, P., \& Hasni, A. (2014). Interest, motivation and attitude towards science and technology at K-12 levels: a systematic review of 12 years of educational research. Studies in Science Education, 50(1), 85-129. doi:10.1080/03057267.2014.881626

Richards-Babb, M., Curtis, R., Ratcliff, B., Roy, A., \& Mikalik, T. (2018). General Chemistry Student Attitudes and Success with Use of Online Homework: Traditional-Responsive versus Adaptive-Responsive. J Chem Educ, 95(5), 691-699. doi:10.1021/acs.jchemed.7b00829

Richards-Babb, M., Drelick, J., Henry, Z., \& Robertson-Honecker, J. (2011). Online Homework, Help or Hindrance? What Students Think and How They Perform. Journal of College Science Teaching, 40(4), 8193.

Schiller, C. F. H. a. N. A. (2013). Case Studies and the Flipped Classroom. Journal of College Science Teaching, $42(5), 62-66$.

Shaw, M. E. (1967). Scales for the measurement of attitudes [by] Marvin E. Shaw [and] Jack M. Wright. New York: New York, McGraw-Hill.

Simpson, R. D. (1975). The Correlation of Selected Affective Behaviors with Cognitive Performance in a Biology Course for Elementary Teachers.

WileyPLUS. (2019, 2019). Case Studies. Retrieved from https://www.wileyplus.com/case-studies/

Willson, V. L. (1983). A meta-analysis of the relationship between science achievement and science attitude: Kindergarten through college. Journal of Research in Science Teaching, 20(9), 839-850.

Woo, Y., \& Reeves, T. C. (2007). Meaningful interaction in web-based learning: A social constructivist interpretation. The Internet and Higher Education, 10(1), 15-25. doi:10.1016/j.iheduc.2006.10.005 